\title{
Efficacy of ixazomib-lenalidomide- dexamethasone in high-molecular-risk relapsed/refractory multiple myeloma - case series and literature review
}

\author{
Aneta Szudy-Szczyrek ${ }^{1, A-F} \oplus$, Sylwia Chocholska ${ }^{1, B-C, F}{ }^{\circ}$, Oliwia Bachanek-Mitura ${ }^{1, B-C, F \oplus}$,

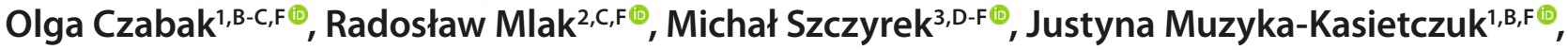 \\ Marek Hus ${ }^{1, E-F} \odot$ \\ ${ }^{1}$ Department of Hematooncology and Bone Marrow Transplantation, Medical University of Lublin, Poland \\ ${ }^{2}$ Department of Human Physiology, Medical University of Lublin, Poland \\ ${ }^{3}$ Chair and Department of Pneumonology, Oncology and Allergology, Medical University of Lublin, Poland \\ A - Research concept and design, B - Collection and/or assembly of data, C - Data analysis and interpretation, \\ $D$ - Writing the article, $E$ - Critical revision of the article, $F$ - Final approval of article
}

\begin{abstract}
Szudy-Szczyrek A, Chocholska S, Bachanek-Mitura O, Czabak O, Mlak R, Szczyrek M, Muzyka-Kasietczuk J, Hus M. Efficacy of ixazomiblenalidomide-dexamethasone in high-molecular-risk relapsed/refractory multiple myeloma - case series and literature review. Ann Agric Environ Med. 2022; 29(1): 103-109. doi: 10.26444/aaem/137788
\end{abstract}

\begin{abstract}
Introduction and objective. Multiple myeloma ( $\mathrm{MM})$ is an incurable condition with variable clinical course. The study included a group of patients with especially poor-prognosis, individuals with relapsed/refractory multiple myeloma (RRMM) and specific cytogenetic disorders. Among the currently used therapies the ixazomib-lenalidomid-dexamethasone (IRd) is considered as a candidate to improve outcomes. The aim of the study was to evaluate the safety and efficacy of IRd regimen in the treatment of patients with RMMM.

Materials and method. Nine patients aged 52-82 years who received ixazomib in the early access programme, were included in the study. All patients met the criteria for recurrent/relapsed MM and had high (t(4:14), t(14:16), del17p or +1q21) risk aberrations. Previous chemotherapy regimens included thalidomide and bortezomib. Median duration of exposure to ixazomib was 12 months.

Results. One patient with multiple cytogenetic aberrations and extramedullary plasmocytoma died because of progression after two months of treatment. In the remaining patients, the objective response to treatment was reached, and in four cases it was qualified as a very good partial response (VGPR). Observed adverse effects included neutropenia, infections, and oedema (in three cases Grade 3). Eight patients continue treatment, in two cases the decision was made to reduce lenalidomide doses.

Conclusions. Preliminary results suggest potentially high efficacy and good safety profile of IRd therapy in patients with RRMM and unfavourable cytogenetics.
\end{abstract}

\section{Key words}

lenalidomide, high risk, ixazomib, cytogenetic, relapsed/refractory multiple myeloma

\section{INTRODUCTION}

Although progress has been made with the introduction of proteasome inhibitors (PI's) and immunomodulatory drugs (IMiD's), therapy of multiple myeloma (MM) still remains a challenge. Treatment response and survival in patients with newly diagnosed multiple myeloma (NDMM) is varied, with survival ranging from 2 to over 10 years. Relapse and disease progression is common, even after a complete remission. Prognosis is influenced by cytogenetic aberrations. High risk cytogenetic abnormalities that can be diagnosed using fluorescence in situ hybridization (FISH) technique include $\mathrm{t}(4 ; 14), \mathrm{t}(14 ; 16), \mathrm{t}(14 ; 20)$ translocations, $17 \mathrm{p}$ deletion $[\operatorname{del}(17 \mathrm{p})]$ and $C K S 1 B$ gene amplification [1-4].

Address for correspondence: Aneta Szudy-Szczyrek, Department of Haematooncology and Bone Marrow Transplantation, Medical University, Staszica Street 11, 20-081 Lublin, Poland

E-mail: anetaszudy@gmail.com

Received: 02.03.2021; accepted: 18.05.2021; first published: 15.06.2021
Among the population of MM patients, those with relapsed/ refractory disease and unfavourable cytogenetics form a group with poor prognosis. Treatment strategies approved for the treatment of RRMM include PI or immunotherapy combined with IMiD's [5]. However, there is still a need for additional therapeutic options that would allow prolonged treatment and disease control.

Ixazomib was the first orally administered PI [6], which when used with lenalidomid and dexamethasone (Rd) has been approved for the treatment of patients with MM after at least one prior line of treatment. In the registration trial, TOURMALINE-MM1 ixazomib brought significant benefit in progression-free survival (PFS) (median 20.6 vs. 14.7 months) and treatment response rate with limited additional toxicity. This allowed the achievement of equal outcomes in patients at standard and high cytogenetic risk [7]. At the time of writing, ixazomib is available in Poland in the early access programme. 


\section{MATERIALS AND METHOD}

Patients. Between September 2018 - June 2020, patients diagnosed with high molecular risk RRMM treated with IRd in the Department of Haematooncology and Bone Marrow Transplantation in Lublin were analysed. The patients received ixazomib via an early access programme. To be eligible for the study, the patients were required tohave been treated previously with 1-3 treatment lines, to have no known resistance to lenalidomide or PIs, and have adequate performance status ( $\leq 2$ in the ECOG scale). Collection and analysis of data was performed independently from the Takeda Pharmaceutical Company. Patients had at least one cytogenetic aberration that was associated with poor prognosis, including: $\operatorname{del}(17 \mathrm{p}), \mathrm{t}(4 ; 14), \mathrm{t}(14 ; 16)$.

All procedures were performed in accordance with the ethical standards of the institutional Research Committee and with the Helsinki Declaration. Local approval was obtained from the Bioethical Committee at the Medical University of Lublin (Consent No. KE-0254/77/2019). All patients gave informed consent to participate in the study.

Cytogenetic assessment. Bone marrow samples were studied. Cytogenetic analyses were performed in the Molecular Laboratory of the Department of Haematooncology and Bone Marrow Transplantation in Lublin.

Abnormalities characteristic of MM, such as TP53 gene deletion, IGH gene rearrangements - $\mathrm{t}(4 ; 14), \mathrm{t}(8 ; 14), \mathrm{t}(11 ; 14)$ and $t(14 ; 16)$, as well as CKS1B gene amplification, were tested by simultaneous staining of cytoplasmic immunoglobulin with the fluorescence in situ hybridization (cIg-FISH) technique according to recommendations of Ross et al, with some modifications [8].

The following probes, all from Abbott Molecular (Abbott Park, IL, USA), were used: Vysis TP53/CEP 17 FISH Probe Kit for detection of del(17p13.1), Vysis IGH/FGFR3 Dual Colour, Dual Fusion Translocation Probe for detection of $\mathrm{t}(4 ; 14)(\mathrm{p} 16 ; \mathrm{q} 32)$, Vysis IGH/MYC/CEP 8 Tri-colur, Dual Fusion Translocation Probe for detection of $\mathrm{t}(8 ; 14)$ (q24;q32), Vysis IGH/CCND1 Dual Colour, Dual Fusion Translocation Probe for detection of $\mathrm{t}(11 ; 14)(\mathrm{q} 13 ; \mathrm{q} 32)$, Vysis IGH/MAF Dual Colour, Dual Fusion Translocation Probe for detection of $\mathrm{t}(14 ; 16)(\mathrm{q} 32 ; \mathrm{q} 23)$ and Vysis 1q21 CKS1B SpectrumOrange/1p32 CDKN2C SpectrumGreen FISH Probe Kit for the detection of amp(1q32). Fluorescent microscopic analysis was performed by scoring 100 AMCApositive plasma cells to determine the frequency of each aberration. Cut-off levels were $20 \%$ for deletion/amplification probes and $10 \%$ for dual fusion probes, according to the recommendations of the European Myeloma Network [8, 9]. Response to treatment was assessed according to the current International Myeloma Working Group (IMWG) guidelines [10].

\section{OBJECTIVES}

The aim of the study was to describe the authors our experiences with treating high molecular risk RRMM patients using the IRd regimen. The primary endpoint was to establish an objective response rate (ORR; partial response $(\mathrm{PR})$ or better), clinical benefit rate (CBR; minimal response (MR) or better) and disease control rate (DCR; stabilisation of disease
(SD) or better). In order to assess the safety of the treatment, time of exposure to ixazomib, treatment interruptions, and frequency of adverse effects (AE) were monitored. Severity of AE was assessed according to the Common Terminology Criteria for Adverse Events (CTCAE) v 5.0.

\section{RESULTS}

Study group. Nine patients were included in the study six men and three women; median age - $71(52-82)$ years. Patients scored either 1 or 2 in the ECOG scale. Six patients were diagnosed with MM with a monoclonal component, there were also two cases of light chain disease, and one case of extramedullary plasmocytoma.

Eight patients had del(17p) deletion in $6-100 \%$ of plasmocytes (median $16 \%$ ), one patient $\mathrm{t}(4 ; 14)$ translocation in $100 \%$ of plasmocytes, and two - ampCKS1B amplifications in $55 \%$ and $100 \%$ of plasmocytes. Translocations $\mathrm{t}(11 ; 14)$ (in $94 \%$ of plasmocytes) and $\mathrm{t}(8 ; 14)$ (in $88 \%$ of plasmocytes) were confirmed in one patient each. In three patients, two high risk abnormalities were present. In seven cases, IRd was given as a second line, and in two patients it was a third line. Previous therapies were based on bortezomib and thalidomide. All patients met the criteria for relapsed MM. None of the patients had undergone prior ASCT.

IRd treatment. Patients were administered $4 \mathrm{mg}$ of ixazomib on days 1,8 and $15 ; 25 \mathrm{mg}$ of lenalidomide on days 1-21; and 20-40 mg of dexamethasone on days $1,8,15$ and 22, in a 28 -day regimen. Lenalidomide dosing in patients with renal insufficiency was reduced according to recommendations. In two patients with estimated Glomerular Filtration Rate (eGFR) below $50 \mathrm{~mL} / \mathrm{min}$, the starting doses of ixazomib was also reduced to $3 \mathrm{mg}$. Patients received antithrombotic, antibacterial and antiviral prophylaxis according to guidelines. Patients recieved additional treatment with intravenous biphosphonians. Median duration of exposure to ixazomib was 12 months. Detailed patient's data and data related to previous treatment are summarized in Table 1.

Response and outcome. Eight of the nine patients achieved objective response after the second treatment cycle [M-protein concentration was reduced by 28 to $72 \%$, clonal serum free light-chains (sFLC) by 38 to $61 \%$ ].

Clinical benefit was achieved by patients who previously received one $(n=6)$ and two $(n=2)$ lines of treatment, regardless of the previous treatment regimen [bortezomibthalidomide-dexamethasone (VTD): $n=2$; bortezomibcyclophosphamide-dexamethasone (VCD): $n=4$; bortezomibdexamethasone (VD): $n=1$; thalidomide-dexamethasone (TD): $n=1)$. The longer time to progression after the first line treatment was associated with clinical response (13 vs. 3 months). At the time of writing, all eight patients who benefited from treatment are still on IRd therapy.

One death occurred due to disease progression after two months of treatment in a patient with two high-risk aberrations: $\operatorname{del}(17 \mathrm{p})$ and $\mathrm{t}(4 ; 14)$. It is worth emphasizing that the presence of $t(4 ; 14)$ was detected in all the plasmocytes. The patient was younger than the median of the study group (66 vs. 71.5 years), in worse performance status (ECOG 2), disease stage III according to the Durie-Salomon classification, and stage 3 according to the ISS scale. He was 
Table 1. Characteristics of study group

\begin{tabular}{lc}
\hline Variable & All patients, N=9 \\
\hline Male/female & $6 / 3$ \\
\hline Age & $71(52-82)$ \\
\hline Diagnosis & 7 \\
MM with a monoclonal component & 2 \\
MM with light chains & 1 \\
Extramedullary plasmacytoma & \\
\hline Disease status & 9 \\
Relapsed & 0 \\
Refractory & \\
\hline Monoclonal protein class & 1 \\
IgA & 6 \\
IgG & 6 \\
\hline Light chain type & \\
Kappa & 3 \\
Lambda & \\
\hline High risk cytogenetic abnormalities (FISH) & 8 \\
del(17p) & 1 \\
(4;14) & 2 \\
chromosome 1 amplification & 2 \\
$\geq 2$ high risk abnormalities & 1 \\
\hline Other cytogenetic abnormalities (FISH) & 1 \\
(11;14) & \\
t(8;14) & \\
\hline
\end{tabular}

the only patient to be diagnosed with MM with IgA heavy chains and multiple extramedullary plasmocytomas. In the previous line of treatment, the patient received sixcycles of VTD chemotherapy, achieved a partial response, and the disease progressed three months after the end of therapy.

Safety profile. The most common adverse events were infections $(n=5$; mainly upper respiratory tract $n=2)$, neutropenia $(n=2)$ and oedema $(n=1)$. Grade 3 events were reported in three patients and included pneumonia $(n=2)$ and neutropenia $(n=1)$. Three patients had no adverse effects. Interruptions in the IRd treatment were required in six patients. The most common causes were grade 2 infections $(n=4)$, grade 3 neutropenia $(n=1)$ and the coexistence of grade 2 infection with grade 2 neutropenia $(n=1)$. In two patients, the lenalidomidedose was reduced due to worsening cardiac failure, and in two patients the doses of dexamethasone were reduced due to symptoms of intolerance - increased glycaemia, anxiety and sleep disturbances. Despite treatment interruptions and drug dose reductions, the patients benefited from therapy.

Detailed data on the clinical response to IRd chemotherapy depending on demographic and clinical variables are presented in Table 2.

\section{DISCUSSION}

In RRMM treatment, new drugs are usually administered alongside traditional cytostatics: PI +/- IMID +/dexamethasone +/- cytostatic drug. The choice of optimal treatment is significantly influenced by the individual characteristic ofthea patient $[11,12,13]$. Risk is assessed based on published criteria. It is estimated that about $20 \%$ of patients do not fully benefit from treatment because of cytogenetic abnormalities, high $\beta$-2-microglublin, low-albumin or highserum LDH. Additional high-risk factors include plasma cell leukemia, extramedullaary plasmocytoma, and early and aggressive relapse $[4,14,15]$.

\begin{tabular}{ll}
\hline ECOG performance status & 3 \\
1 & 6 \\
\hline & 0 \\
\hline Durie-Salmon stage & 1 \\
III & 8 \\
\hline III & \\
\hline ISS stage & 0 \\
1 & 6 \\
2 & 3 \\
3 & \\
\hline Creatinine clearance, mL/min & 1 \\
$<30$ & 1 \\
$30-50$ & 7 \\
$>50$ & $16(7-70)$ \\
\hline Median time from start of first-line treatment to start of IRd, & \\
months (range) & 7 \\
\hline Treatment lines prior to IRd & 2 \\
1 & \\
2 & 3 \\
\hline Therapy regimens received prior to IRd & 5 \\
Bortezomib-thalidomide-dexamethasone & 1 \\
Bortezomib-cyclophosphamide-dexamethasone & 1 \\
Bortezomib-dexamethasone & 1 \\
Cyclophosphamide-thalidomide-dexamethasone & 0 \\
Thalidomide-dexamethasone & \\
\hline Prior ASCT & \\
\hline
\end{tabular}

Current advances in RRMM treatment are related to recently approved treatment regimens, such as IRd, and regimens based on carfilzomib, pomalidomide or monoclonal antibodies (daratumumab, elotuzumab). These treatment regimens are increasingly used in day-to-day practice, replacing treatment options based on bortezomib or lenalidomide [16, 17].

Ixazomib is the first orally administered PI recommended for RRMM treatment by the Food and Drug Administration (FDA) in the USA in 2015, and the European Medicines Agency (EMA) in 2016. The drug was registered based on the results of the phase 3 TOURMALINE-MM1 study, in which superiority of IRd over placebo-Rd was shown. Total response rate was $78 \%$ in the IRd group and $72 \%$ in the placebo-Rd group, complete response (CR) and VGPR were $48 \%$ and $39 \%$, respectively. Significant improvement in median PFS was achieved (20.6 months vs. 14.7 months, hazard ratio (HR) $0.74 ; \mathrm{p}=0.01$ ). Benefit, understood as improvement in PFS, was observed in all defined subgroups of patients, including those with high risk cytogenetic abnormalities. The study group included 137 patients with $t(4 ; 14)$ and $t(14 ; 16)$ translocations in at least $3 \%$ of plasmocytes and $\operatorname{del}(17 \mathrm{p})$ deletion in 5\% of cells. Relevant improvement in PFS median after ixazomib (21.4 vs 9.7 months, $\mathrm{p}=0.02)$ was discovered. What is particularly important is that ixazomib treatment led to equalization of outcomes in patients with standard and high cytogenetic risk (PFS median 21.4 and 20.6 month) $[7,18]$.

In the TOURMALINE-MM1 study, among high risk patients treated with ixazomib there was a lower number of deaths than in the placebo group (15/75 and 24/62, respectively). Adverse events were the reason to stop therapy in $17 \%$ of patients in the IRd group and $14 \%$ of patients in the placebo-Rd group. Thrombocytopenia was noted in $31 \%$ of patients treated with ixazomib and $16 \%$ in the placebo group; stage 3 and 4 of thrombocytopenia was more common in the IRd group (12\% and 7\% accordingly), compared to placebo-Rd (5\% and $4 \%$, accordingly). Frequency of platelet transfusion 
Table 2. Clinical response depending on selected demographic and clinical variables

\begin{tabular}{|c|c|c|}
\hline \multirow[b]{2}{*}{ Variable } & \multicolumn{2}{|c|}{ Clinical response } \\
\hline & $\begin{array}{c}\text { No } \\
\text { (1 patient) }\end{array}$ & $\begin{array}{c}\text { Yes } \\
\text { (8 patients) }\end{array}$ \\
\hline $\begin{array}{l}\text { Gender } \\
\text { Male } \\
\text { Female }\end{array}$ & $\begin{array}{l}1 \\
0\end{array}$ & $\begin{array}{l}5 \\
3\end{array}$ \\
\hline Age (median [range]) & 65 & $69.5(52-81)$ \\
\hline $\begin{array}{l}\text { Diagnosis } \\
\text { MM with a monoclonal component } \\
\text { MM with light chains } \\
\text { Extramedullary plasmacytoma }\end{array}$ & $\begin{array}{l}0 \\
0 \\
1\end{array}$ & $\begin{array}{l}6 \\
2 \\
0\end{array}$ \\
\hline $\begin{array}{l}\text { Disease status } \\
\text { Relapsed }\end{array}$ & 1 & 8 \\
\hline $\begin{array}{l}\text { Monoclonal protein class } \\
\lg A \\
\operatorname{lgG}\end{array}$ & $\begin{array}{l}1 \\
0\end{array}$ & $\begin{array}{l}0 \\
6\end{array}$ \\
\hline $\begin{array}{l}\text { Light chain type } \\
\text { Kappa } \\
\text { Lambda }\end{array}$ & $\begin{array}{l}1 \\
0\end{array}$ & $\begin{array}{l}5 \\
3\end{array}$ \\
\hline del(17p) (\%) & 6 & $16(6-100)$ \\
\hline $\mathrm{t}(4 ; 14)(\%)$ & 100 & 0 \\
\hline $\begin{array}{l}\geq 2 \text { high risk abnormalities } \\
\text { Yes } \\
\text { No }\end{array}$ & $\begin{array}{l}1 \\
0\end{array}$ & $\begin{array}{l}2 \\
6\end{array}$ \\
\hline $\begin{array}{l}\text { Other cytogenetic aberrations (e.g. } t(11 ; 14) \text {; } \\
\mathrm{t}(8 ; 14)) \\
\text { Yes } \\
\text { No }\end{array}$ & $\begin{array}{l}0 \\
1\end{array}$ & $\begin{array}{l}4 \\
4\end{array}$ \\
\hline $\begin{array}{l}\text { ECOG performance status at the start of Ird } \\
\text { therapy } \\
1 \\
2\end{array}$ & $\begin{array}{l}0 \\
1\end{array}$ & $\begin{array}{l}3 \\
6\end{array}$ \\
\hline $\begin{array}{l}\text { Durie-Salmon stage } \\
\text { I } \\
\text { II } \\
\text { III }\end{array}$ & $\begin{array}{l}0 \\
0 \\
1\end{array}$ & $\begin{array}{l}0 \\
2 \\
6\end{array}$ \\
\hline $\begin{array}{l}\text { ISS stage } \\
2 \\
3\end{array}$ & $\begin{array}{l}0 \\
1\end{array}$ & $\begin{array}{l}6 \\
2\end{array}$ \\
\hline $\begin{array}{l}\text { Creatinine clearance, } \mathrm{mL} / \mathrm{min} \\
<50 \\
>50\end{array}$ & $\begin{array}{l}0 \\
1\end{array}$ & $\begin{array}{l}1 \\
7\end{array}$ \\
\hline $\begin{array}{l}\text { Median time from start of first-line treatment } \\
\text { to start of IRd, months (range) }\end{array}$ & 9 & $16.5(7-72)$ \\
\hline
\end{tabular}

\begin{tabular}{|c|c|c|}
\hline \multirow[b]{2}{*}{ Variable } & \multicolumn{2}{|c|}{ Clinical response } \\
\hline & $\begin{array}{c}\text { No } \\
\text { (1 patient) }\end{array}$ & $\begin{array}{c}\text { Yes } \\
\text { (8 patients) }\end{array}$ \\
\hline $\begin{array}{l}\text { Treatment lines prior to IRd } \\
1 \\
2 \\
\end{array}$ & $\begin{array}{l}1 \\
0\end{array}$ & $\begin{array}{l}6 \\
2\end{array}$ \\
\hline $\begin{array}{l}\text { Prior first line chemotherapy regimen } \\
\text { Cyclophosphamide-thalidomide- } \\
\text { dexamethasone } \\
\text { Bortezomib-thalidomide-dexamethasone } \\
\text { Bortezomib-cyclophosphamide- } \\
\text { dexamethasone }\end{array}$ & $\begin{array}{l}0 \\
1 \\
0\end{array}$ & $\begin{array}{l}1 \\
2 \\
5\end{array}$ \\
\hline Number of first line chemotherapy cycles & 6 & $6.5(5-8)$ \\
\hline Duration of first line treatment [months] & 6 & $7(4-12)$ \\
\hline $\begin{array}{l}\text { Time to progression after first line treatment } \\
\text { [months] }\end{array}$ & 3 & $13(2-30)$ \\
\hline Age at the time of start of IRd chemotherapy & 66 & $71.5(52-82)$ \\
\hline $\begin{array}{l}\text { M-protein concentration before IRd } \\
\text { chemotherapy }(\mathrm{g} / \mathrm{dl})\end{array}$ & 1.25 & $1.635(1.09-2.41)$ \\
\hline $\begin{array}{l}\text { Clonal sFLC concentration before Ird } \\
\text { chemotherapy }(\mathrm{mg} / \mathrm{l})\end{array}$ & 35.81 & $56.81(9.49-1204.06)$ \\
\hline $\begin{array}{l}\text { Haemoglobin (HGB) concentration before IRd } \\
\text { chemotherapy }(\mathrm{g} / \mathrm{dl})\end{array}$ & 8.3 & $11.55(9.2-14.5)$ \\
\hline Platelets (PLT) before IRd chemotherapy (K/ul) & 170 & $221(96-302)$ \\
\hline $\begin{array}{l}\text { Creatinine concentration before IRd } \\
\text { chemotherapy ( } \mathrm{N}: 0.2-., 2 \mathrm{mg} / \mathrm{dl})\end{array}$ & 1.04 & $1.07(0.81-4.27)$ \\
\hline Calcium before treatment $(\mathrm{N}: 2.2-2.55 \mathrm{mmol} / \mathrm{l})$ & 2.39 & $2.32(2.2-2.46)$ \\
\hline Duration of IRd chemotherapy [months] & 2 & $14(7-20)$ \\
\hline Interruptions in IRd chemotherapy & & \\
\hline No & 1 & 2 \\
\hline Yes & 0 & 6 \\
\hline Interruptions in IRd chemotherapy [causes] & & \\
\hline Infections & & 4 \\
\hline Grade 3 neutropenia & & 1 \\
\hline Grade 2 infection with grade 2 neutropenia & & 1 \\
\hline Interruptions in IRd chemotherapy [months] & 0 & $1.5(0.5-3)$ \\
\hline Disease progression & & \\
\hline No & 0 & 8 \\
\hline Yes & 1 & 0 \\
\hline Death & & \\
\hline No & 0 & 8 \\
\hline Yes & 1 & 0 \\
\hline
\end{tabular}

was comparable in both groups ( $8 \%$ and $6 \%$, respectively). The situation was similar in the case of severe adverse effects related to thrombocytopenia ( $2 \%$ in each group) and necessity of treatment cessation because of toxicity $(1 \%$ in each group). The most common non-haematological adverse effects in both groups were gastrointestinal disorders and rash. Gastrointestinal adverse effects were more common in the IRd group comparted to the placebo-Rd group, but were observed mainly in the first three months of therapy, had low intensity, and were alleviated by symptomatic treatment. Rash was observed in $36 \%$ of patients in the ixazomib group and $23 \%$ in the placebo-Rd group; symptoms were noted mainly during the first three months of therapy and were frequently self-limiting. Peripheral polyneuropathy occurred in $27 \%$ of patients in the IRd group and $22 \%$ in the placebo-Rd group. In both groups, these symptoms were mostly grade 1 or 2 , and grade 3 only in $2 \%$ of patients. There were no differences between the two groups regarding the frequency of cardiac failure, arrhythmia, hypertension and myocardial infarction. In the 23-months long analysis there were no significant differences in frequency of secondary neoplasm. The quality of life of the patients was similar in both groups $[7,18,19]$.

According to the consensus of the IMWG (2016) in patients with RRMM and high risk cytogenetic mutations, the use of a 3-drug regimen that includes IMiD and PI is advised [3]. Previous observations proved that Rd treatment is suboptimal in this patient population $[3,19,20]$. It was proven that an unfavourable prognosis related to del(17p) was improved by prolonged administration of bortezomib [21]. However, benefits from prolonged bortezomib therapy seems to be severely limited because of its toxicity profile $[22,23]$. It was also proven that the addition of carfilizomib to Rd brought clinical benefit in a group of patients with high molecular risk, although the results were worse than in case of standard risk patients [20]. In the TOURMALINEMM1 study patients continued IRd therapy until disease progression or unacceptable toxicity occurred. Efficacy, good risk profile, oral administration, and the ntial of prolonged treatment led to similar results in patients a standard and high risk $[7,19]$.

The mechanism of PI action in patients with high molecular risk MM is not fully understood, although there is a hypothesis that increased efficacy in patients with del(17p) and loss of one allele of p53 gene is related to increased level of p53 protein resulting from inhibition of proteasome activity 
which results in apoptosis $[23,24,25,26]$. It is suggested that prolonged proteasome inhibition may lead to maintaining the activity of this important neoplasm inhibitor.

The influence of the size of cell clone with high risk traits on treatment effects remain unclear [27]. In recent publications in which an analysis of new therapies was conducted, the threshold for detecting cytogenetic abnormalities was highly variable, from the presence of changes in single cells in ELOQUENT-2 [28], 1.5\% -7.5\% in the S0777 study [29], to $60 \%$ of cells in the RE study [20]. Interpretation of the results remains difficult. Interestingly, the TOURMALINE-MM1 study demonstrated that the benefit in relation to PFS was constant and did not depend on the size of cell clone with del(17p), $t(4 ; 14)$ and amp(1q21). It was shown that median PFS was similar for two different thresholds for detecting del(17p), 5\% and 20\% (in both cases 21.4 months, HR $0.490-$ $0.61)$. In post hoc analysis it was found that in patients with a $\operatorname{del}(17 \mathrm{p})$ threshold value of $60 \%$, the median PFS was shorter (15.7 months); however, because of the small size of the study group, the authors suggested cautious interpretation of the data. In all cases, significant improvement relative to the patients treated with placebo-Rd was observed (PFS median for $5 \%, 20 \%$ and $60 \%$ thresholds was 9.7, 6.7 and 5.1 month, respectively). Among patients with $\mathrm{t}(4 ; 14)$, the benefit from ixazomib treatment was observed in patients with 3\%, 20\% and $60 \%$ thresholds (HR 0.518-0.685) $[18,19]$.

In the current study group, del(17p) was present in both responders and non-responders. In a patient who did not benefit from treatment, the percentage of plasmacytes with $\operatorname{del}(17 \mathrm{p})$ was 6\%, lower than in responders (median 16\%). The presence of $t(4 ; 14)$ was associated with a lack of response to treatment - the only patient with a lack of response was a carrier of this mutation; however, it was not found in any of the eight patients who benefited from treatment. Translocation $t(14 ; 16)$ was not found in any of the examined patients. The presence of $\mathrm{t}(11 ; 14)$ or $\mathrm{t}(8 ; 14)$ did not affect the efficacy of treatment. While $t(11 ; 14)(\mathrm{q} 13 ; \mathrm{q} 32)$ is the most common translocation in MM patients, one of the less common cytogenetic disorders, $\mathrm{t}(8 ; 14)(\mathrm{q} 24 ; \mathrm{q} 32)$, is associated with MYC oncogene rearrangement. Both changes are still considered aberrations of unknown prognostic significance. However, there are single reports noting that the presence of $t(8 ; 14)$ and $t(11 ; 14)$, especially with the coexistence of other high risk aberrations, may be associated with an unfavouable prognosis in patients with MM [30, 31, 32].

According to the consensus of the IMWG (2016), amp(1q21) was added to high risk cytogenetic aberrations in MM $[5,33$, 34]. In the TOURMALINE-MM1 study, post hoc analysis was performed in order to assess the effects of treatment in patients with this mutation. Acquired data suggests benefit in relation to PFS median in patients treated with IRd vs. placebo-Rd with both isolated amp(1q21) (3\% threshold; HR, $0.781 ; 95 \% \mathrm{CI}, 0.492-1.240)$, and in the group at extended high risk ( $\geq 2$ changes, HR 0.644 ; 95\% CI 0,474-0.928). Interestingly, the improvement of median PFS with IRd relative to placebo-Rd seems to be somewhat shorter in the group with isolated change. These observations indicate the need for further research. It is suggested that $\operatorname{amp}(1 \mathrm{q} 21)$ commonly coexists with other cytogenetic abnormalities, such as del(1p), which may also lead to worse treatment outcomes.

Dash et al. demonstrated that the addition of ixazomib to $\mathrm{Rd}$ brings clinical benefit in patients with MM with non-canonical NF- $\kappa \mathrm{B}$ pathway activation, which is a suggested mechanism of activity in high-risk MM with 1q21 amplification. The authors used DNA/RNA sequencing data from 339 patients in the phase III TOURMALINEMM1 study. In 49 patients, non-canonical NF- $\kappa B$ pathway mutations were found. In those patients PFS was significantly longer in the IRd group compared to placebo-Rd group (HR $0.23)$ [35]. In the current study, amp(1q21) was detected in two patients - in $55 \%$ and $100 \%$ of plasmocytes. In those patients, administering IRd triplet brought clinical benefit, but limited only to SD.

The first real world data about IRd use in a group of 30 patients treated at the UK Haematology Centre were presented in 2017 during European Haematology Association Conference. Median age of patients - 65 years, median number of previous treatment lines - 2 (2-5), with all patients previously treated with PI (29 with bortezomib and five with carfilzomib); eight were resistant to therapy. Three patients had previously received lenalidomide. In 23 patients, ASCT was performed. Eighteen patients had unfavourable cytogenetic aberrations, among whom six were characterized by loss of TP53 protein. The median number of completed treatment cycles was 6. ORR - 70.8\% (PR 13 (54.1\%), VGPR 3 (12.5\%), CR 1 (4.2\%)). For patients resistant to previous PI therapy, ORR was 37.5\% (PR 2 (25\%), VGPR 1 (12.5\%)). PFS median in patients with TP53 loss was 7.5 months. IRd therapy was well tolerated. In five cases neutropenia and thrombocytopenia of stages 3-4 was observed, one patient had been diagnosed with anaemia stage 4 . Because of toxicity, the ixazomib dose was reduced in four patients and treatment was stopped in one [36].

Hajek et al. presented data about IRd therapy in RRMM from the Insight MM Observational Study and the Czech Registry of Monoclonal Gammopathies (RMG). 163 patients from nine countries (50 INSIGHT MM, 113 from Czech RMG) were included in the analysis. Age median was 67 years (range: $39-84$ ), $71 \%$ had ECOG PS $\geq 1$. Median time between diagnosis and the beginning of treatment with IRd was 42.6 months. A total of 50\% / 30\% / 20\% patients had been administered IRd as a therapy of the $2 / 3 / \geq 4$ line. Previous therapies included bortezomib in $89 \%$ patients, thalidomide in $42 \%$, lenalidomide in $21 \%$, carfilzomib in $11 \%$, daratumumab in $3 \%$ and pomalidomide in $2 \% .61 \%$ of patients who had undergone bone marrow transplantation before the analysed therapy. Data about the best response to treatment was available in 105 patients, among whom ORR was achieved in $74 \%$, and $\geq V$ VPR in $31 \%$ of patients. Median PFS was 20.9 months (95\% CI: 13.0-28.7). Median overall survival (OS) was not reached. Reduction of ixazomib and lenalidomide doses was required in $15 \%$ and $30 \%$ of patients, respectively; however, only in $11 \%$ and $21 \%$ it was caused by toxicity [37].

Terpos et al. published new real-world data about the efficacy of IRd in RRMM. The study was conducted on a group of 155 patients who received ixazomib via an early access programme in Greece, UK, and the Czech Republic; median age -68 years; $17 \%$ had ECOG $\geq 2$; median number of previous therapies was one (range: $1-7$ ); $91 \%, 47 \%$ and $17 \%$ received bortezomib, thalidomide and lenalidomide, respectively. Median duration of exposure to ixazomib was 9.6 months. Total response rate was $74 \%$, including $35 \%$ of VGPR or better (including 16\% CR). Median PFS reached 27.6 months. IRd treatment for more than six months was 
related to prolonged PFS (HR 0,06). In $9 \%$ of patients, the treatment was stopped because of adverse events with no disease progression. Peripheral neuropathy occurred in $35 \%$ of patients (3\% grade $3-4)$. Observations were consistent with the results of the TOURMALINE-MM1 study on a bigger patient population in a real-world setting. Because of the lack of routinely conducted cytogenetic tests, analysis of treatment efficacy in high molecular risk patients was not performed [38].

In a study comparing the effectiveness of IRd versus $\mathrm{Rd}$ in patients with relapsed and refractory multiple myeloma (RRMM), Minarik et al. confirmed the results of the TOURMALINE-MM1 study. The study involved 344 patients, 127 treated with IRd and $217 \mathrm{Rd}$. The median PFS for the IRd was 17.5 months, and for the Rd 11.5 months ( $\mathrm{p}=0.005)$, median OS 36.6 months vs.26.0 months ( $\mathrm{p}=0.008)$. ORR was $73.0 \%$ in the IRd group vs. $66.2 \%$ in the Rd group. The IRd regimen was most beneficial in patients $\leq 75$ years of age with ISS I, II, and after the first and second relapses. Patients with extramedullary disease did not benefit from IRD treatment (median PFS 6.5 months). Both regimens were well tolerated and the incidence of any and grade $3 / 4$ toxicity was comparable. High-risk abberations $(\mathrm{t}(4 ; 14), \mathrm{t}(14$; $16)$, or $\operatorname{del}(17 \mathrm{p} 13))$ occurred in $11.8 \%(15 / 127)$ of patients in the IRd cohort and $8.8 \%(19 / 217)$ of patients treated with $\mathrm{Rd}$. In the high-risk group of RRMM patients, one patient achieved VGPR, six PR, four MR, two had SD, and two progressive disease (PD). Among patients in the $\mathrm{Rd}$ cohort whose disease was considered to be high risk, one patient achieved VGPR, seven - PR, five - MR, three maintained $\mathrm{SD}$, and three progressed [39].

Cohen et al. presented the results of ixazomib-based combination treatment in patients with RRMM in a realworld setting. The study group consisted of 78 patients from 7 participating sites from the Israeli registry, $82 \%$ of whom used the IRd scheme. In 13 patients, ixazomib was used in $\geq 4$ th line of treatment. 29 patients were diagnosed with high-risk cytogenetic disorders ( $\mathrm{t}(4: 14), \mathrm{t}(14: 16)$, del17p, or $+1 \mathrm{q} 21)$. The treatment was relatively well tolerated, $11 \%$ of patients discontinued therapy due to toxicity. Median PFS on ixazomib reached 24 months (95\% CI 17-30), median OS was not reached. Higher LDH, older age, and aggressive course of the disease were associated with worse PFS, while a deeper response to ixazomib ( $\geq$ VGPR) and a longer firstline bortezomib response ( $\geq 24$ months) were associated with improved PFS. Interestingly, there was no effect on PFS depending on cytogenetic risk according to FISH disease stage according to ISS/rISS classification and previously used therapies [40].

Surprisingly, a recently published, large real-world data study of IRd therapy in RRMM patients in Asia presented different results than those of TOURMALINE-MM1. The study included 122 patients from 16 centres of the Kansai Myeloma Forum database. Median age was 72 years, median of prior chemotherapy lines was four. Bortezomib had been previously used in $85.4 \%$ and lenalidomide in $89.3 \%$ patients. The treatment was stopped due to disease progression in 46 and adverse events in 32 cases. Median PFS was 11.9 months while median OS was not reached. IRd regimen showed poor efficacy, especially in patients without the IgG M-protein component and refractory to lenalidomide [41].

\section{CONCLUSIONS}

Molecular abberations are one of the most important prognostic factors in patients with MM. Patients with relapsed/refractory disease and unfavourable cytogenetic abberations have a particularly poor prognosis. The outcome is highly dependent on the treatment strategy. Data from the TOURMALINE-MM1 study and real-world observations indicate that in the presence of high-risk specific cytogenetic abnormalities such as del(17p), $t(4 ; 14), t(14 ; 16)$, the use of the IRd treatment regimen should be considered. It seems to be a very promising option with high efficacy and good tolerance; however, a large randomized trial comparing the effectiveness of new anti-myeloma drugs, especially in patients with cytogenetic abnormalities, is still lacking.

\section{REFERENCES}

1. Kazmi SM, Nusrat M, Gunaydin H, et al. Outcomes among high-risk and standard-risk multiple myeloma patients treated with high-dose chemotherapy and autologous hematopoietic stem-cell transplantation. Clin Lymphoma Myeloma Leuk. 2015; 15(11): 687-693.

2. Mikhael JR, Dingli D, Roy V, et al. Management of newly diagnosed symptomatic multiple myeloma: updated Mayo Stratification of Myeloma and Risk-Adapted Therapy (mSMART) consensus guidelines 2013. Mayo Clin Proc. 2013; 88(4): 360-376.

3. Sonneveld P, Avet-Loiseau H, Lonial S, et al. Treatment of multiple myeloma with high-risk cytogenetics: a consensus of the International Myeloma Working Group. Blood. 2016; 127(24): 2955-2962.

4. Fonseca R, Bergsagel PL, Drach J, et al. International Myeloma Working Group. International Myeloma Working Group molecular classification of multiple myeloma: spotlight review. Leukemia. 2009; 23(12): 2210-2221.

5. Kuiper R, van Duin M, van Vliet MH, et al. Prediction of high- and lowrisk multiple myeloma based on gene expression and the International Staging System. Blood. 2015; 126(17): 1996-2004.

6. Gupta N, Hanley MJ, Xia C, et al. Clinical pharmacology of Ixazomib: the first oral proteasome inhibitor. Clin Pharmacokinet. 2019; 58(4): 431-449.

7. Moreau P, Masszi T, Grzasko N, et al. Oral ixazomib, lenalidomide, and dexamethasone for multiple myeloma. N Engl J Med. 2016; 374(17): 1621-1634.

8. Ross F, Avet-Loiseau H, Ameye G, et al. Report from the european myeloma network on interphase fish in multiple myeloma and related disorders. Haematologica. 2012; 97(8): 1272-1277.

9. Dmoszynska A, Chocholska S. Molecular biology methods in the diagnosis of multiple myeloma, In: Witt M, Dawidowska M, Szczepanski T. editors, 2012. Molecular Aspects of Hematologic Malignancies: Diagnostic Tools and Clinical Applications. Berlin Heidelberg: Springer-Verlag 443-449.

10. Kumar S, Paiva B, Anderson KC, et al. International Myeloma Working Group consensus criteria for response and minimal residual disease assessment in multiple myeloma. The Lancet Oncology. 2016; 17: e328-e346.

11. Kumar SK, Dispenzieri A, Lacy MQ, et al. Continued improvement in survival in multiple myeloma: changes in early mortality and outcomes in older patients. Leukemia. 2014; 28(5): 1122-1128.

12. Palumbo A, Avet-Loiseau H, Oliva S, et al. Revised International Staging System for Multiple Myeloma: a report from International Myeloma Working Group. J Clin Oncol. 2015; 33(26): 2863-2869.

13. Maiese EM, Ainsworth C, Le Moine JG, et al. Comparative efficacy of treatments for previously treated multiple myeloma: a systematic literature review and network meta-analysis. Clin Ther. 2018; 40(3): 480-494.

14. Chim CS, Kumar SK, Orlowski RZ, et al. Management of relapsed and refractory multiple myeloma: novel agents, antibodies, immunotherapies and beyond. Leukemia. 2018; 32(2): 252-262.

15. Harousseau JL, Attal M. How I treat first relapse of myeloma. Blood. 2017; 130(8): 963-973.

16. Jagannath S, Abonour R, Durie BGM, et al. Heterogeneity of secondline treatment for patients with multiple myeloma in the connect $\mathrm{MM}$ 
registry (2010-2016). Clin Lymphoma Myeloma Leuk. 2018; 18(7): 480-485.

17. Chari A, Romanus D, Palumbo A, et al. Randomized Clinical Trial Representativeness and Outcomes in Real-World Patients: Comparison of 6 Hallmark Randomized Clinical Trials of Relapsed/Refractory Multiple Myeloma. Clin Lymphoma Myeloma Leuk. 2020; 20(1): 8-17.

18. Richardson PG, Avet-Loiseau H, Palumbo A, et al. Efficacy and safety of ixazomib plus lenalidomide-dexamethasone (IRd) vs placebo-rd in patients (pts) with relapsed/refractory multiple myeloma (RRMM) by cytogenetic risk status in the global phase III Tourmaline-MM1 study. J Clin Oncol. 2016; 34(suppl): 8018.

19. Avet-Loiseau H, Bahlis NJ, Chng WJ, et al. Ixazomib significantly prolongs progression-free survival in high-risk relapsed/refractory myeloma patients. Blood. 2017; 130: 2610-2618.

20. Avet-Loiseau H, Fonseca R, Siegel D, et al. Carfilzomib significantly improves the progression-free survival of high-risk patients in multiple myeloma. Blood. 2016; 128(9): 1174-1180.

21. Neben K, Lokhorst HM, Jauch A, et al. Administration of bortezomib before and after autologous stem cell transplantation improves outcome in multiple myeloma patients with deletion 17p. Blood. 2012; 119(4): 940-948.

22. Avet-Loiseau H, Leleu X, Roussel M, et al. Bortezomib plus dexamethasone induction improves outcome of patients with $t(4 ; 14)$ myeloma but not outcome of patients with del(17p). J Clin Oncol. 2010; 28(30): 4630-4634.

23. Mateos MV, Oriol A, Mart'inez-L 'opez J, et al. Maintenance therapy with bortezomib plus thalidomide or bortezomib plus prednisone in elderly multiple myeloma patients included in the GEM2005MAS65 trial. Blood. 2012; 120(13): 2581-2588.

24. Ling YH, Liebes L, Ng B, et al. PS-341, a novel proteasome inhibitor, induces Bcl-2 phosphorylation and cleavage in association with G2-M phase arrest and apoptosis. Mol Cancer Ther. 2002; 1(10): 841-849.

25. Ling YH, Liebes L, Jiang JD, et al. Mechanisms of proteasome inhibitor PS-341-induced G(2)-Mphase arrest and apoptosis in human non-small cell lung cancer cell lines. Clin Cancer Res. 2003; 9(3): 1145-1154.

26. Herrero AB, Rojas EA, Misiewicz-Krzeminska I, et al. Molecular mechanisms of p53 deregulation in cancer: an overview in multiple myeloma. Int J Mol Sci. 2016; 17(12): E2003.

27. An G, Li Z, Tai YT, et al. The impact of clone size on the prognostic value of chromosome aberrations by fluorescence in situ hybridization in multiple myeloma. Clin Cancer Res. 2015; 21(9): 2148-2156.

28. Lonial S, Dimopoulos M, Palumbo A, et al. ELOQUENT-2 Investigators. Elotuzumab therapy for relapsed or refractory multiple myeloma. N Engl J Med. 2015; 373(7): 621-631.

29. Durie BG, Hoering A, Abidi MH, et al. Bortezomib with lenalidomide and dexamethasone versus lenalidomide and dexamethasone alone in patients with newly diagnosed myeloma without intent for immediate autologous stem-cell transplant (SWOG S0777): a randomised, openlabel, phase 3 trial. Lancet. 2017; 389(10068): 519-527.

30. Tomas P, Miroslava V, Jiri M, et al. Translocation $t(8 ; 14)$ in multiple myeloma defines patients with very poor prognosis - single centre experience. Cl Lymph Myelom Leuk. 2015; 15: e122-e122.

31. Paner A, Patel P, Dhakal B. The evolving role of translocation $t(11 ; 14)$ in the biology, prognosis, and management of multiple myeloma. Blood Rev. 2020; 41: 100643.

32. Leiba M, Duek A, Amariglio N, et al. Translocation t(11;14) in newly diagnosed patients with multiple myeloma: Is it always favorable? Genes Chromosomes Cancer. 2016; 55(9): 710-718.

33. Boyd KD, Ross FM, Chiecchio L et al. A novel prognostic model in myeloma based on cosegregating adverse FISH lesions and the ISS: analysis of patients treated in the MRC Myeloma IX trial. Leukemia. 2012; 26(2): 349-355.

34. Nahi $\mathrm{H}, \mathrm{V}^{\circ}$ atsveen TK, Lund J, et al. Proteasome inhibitors and IMiDs can overcome some high-risk cytogenetics in multiple myeloma but not gain 1q21. Eur J Haematol. 2016; 96(1): 46-54.

35. Dash AB, Zhang J, Shen L, et al. Clinical benefit of ixazomib plus lenalidomide-dexamethasone in myeloma patients with non-canonical NF- $\kappa$ B pathway activation. Eur J Haematol. 2020; 105(3): 274-285.

36. Ziff M, Cheesman S, Kyriakou Ch, et al. Real world use of ixazomib with lenalidomide and dexamethasone for patients with relapsed and relapsed refractory multiple myeloma. EHA Library. 2017; 05/18/17;182689; PB1975.

37. Hajek R, Terpos E, Lee HC, et al. Ixazomib plusl-dexamethasone (IRd) in relapsed/refractory multiple myeloma (MM) patients (Pts)effectiveness in routine clinical practice is similar to the efficacy in the phase 3 tourmaline-MM1 trial: a pooled analysis from the insight MM observational study and the Czech registry of monoclonal gammopathies (RMG). Blood. 2018; 132(Suppl 1): 1971.

38. Terpos E, Ramasamy K, Maouche N, et al. Real-world Effectiveness and Safety of Ixazomib-Lenalidomide-Dexamethasone in relapsed/ refractory Multiple Myeloma. Ann Hematol. 2020; 99(5): 1049-1061.

39. Minarik J, Pika T, Radocha J, et al. Survival benefit of ixazomib, lenalidomide and dexamethasone (IRD) over lenalidomide and dexamethasone $(\mathrm{Rd})$ in relapsed and refractory multiple myeloma patients in routine clinical practice. BMC Cancer, 2021; 21(1): 73.

40. Cohen YC, Magen H, Lavi N, et al. Ixazomib-based regimens for relapsed/refractory multiple myeloma: are real-world data compatible with clinical trial outcomes? A multi-site Israeli registry study. Ann Hematol. 2020; 99(6): 1273-1281.

41. Takakuwa T, Yamamura R, Ohta K, et al. Outcomes of ixazomib/ lenalidomide/dexamethasone for multiple myeloma: A multicenter retrospective analysis. Eur J Haematol. 2021; 106(4): 555-562. 